\title{
TEIXEIRA DE FREITAS E O CODIGO CIVIL ARGENTINO
}

A contribuição argentina para as festas do centenario da criação dos cursos juridicos no Brasil imprimiu-lhes uma nota de cordialidade sul americana, que muito nos sensibilizou. Advogados argentinos aqui estiveram coparticipando de nosso jubilo, tornando mais affectuosa a grande e luminosa solidariedade espiritual que une as duas republicas, cuja historia contém paginas em que os seus dois grandes povos, unidos, batalharam pelo mesmo ideal e pelas mesmas causas. Tem a tradição, como se vê, muita força, e o seu prestigio, posto invisivel nos factos diversos da vida diaria dos dois paizes, se revela nos seus grandes acontecimentos.

Entre os centros da cultura argentina, Cordoba, a cidade provinciana, occupa logar saliente. Sua Universidade Nacional, tricentenaria, nucleo universitario dos mais antigos da America, conserva, no correr dos annos, a sua significação nacional, que a sua longa existencia mantém e aprimora, para a marcha ascencional do pensamento e da civilização argentina.

Dalli partiu uma das mais suggestivas commemorações do centenario dos cursos juridicos de S. Paulo e de Olinda, devida a EnRIQue Martinez Paz, professor de Direito Civil Comparado e de Philosophia do Direito, em livro, dado á publicidade em 11 de agosto deste anno: Freitas y 
su influencia sobre el Código Civil Argientino, em que inscreveu esta dedicatoria:

"A la Universidad de Rio de Janeiro en reconocimiento, $y$ a los juristas brasileños como expresion de solidaridad espiritual, en ocasion del primer centenario de la fundacion de los cursos juridicos en San Paulo y Olinda"

Tem, neste livro generoso, escripto com enthusiasmo e com orgulho, que se poderia dizer continental, a sua merecida consagração, a cultura juridica brasileira, atravez da obra genial de Augusto TeiXeira de Freitas, o Cujacio brasileiro.

Se outras affinidades, de raça e de historia, não existissem entre a Republica Argentina e o Brasil, por certo que a da sua legislação civil, oriunda das mesmas fontes, seria sufficiente para entretecer, nas relações dos dois paizes, uma meada commum de sentimentos.

Sabem todos que a influencia de TeIXEIRA DE Freitas foi sensivel na elaboração do projecto que se converteu no codigo civil argentino. Este livro diz, como serenidade e com justiça, do alto grau dessa influencia, dando mostras da magnanimidade de espirito dos juristas argentinos contemporaneos. Começa por lembrar que, de uma feita, VÉLEZ SÁRSFIELD, o grande codificador argentino,natural de Córdoba, communicara a TEIXEIRA DE FREITAS — em carta, a que JOAQUIM NABUCO se referiu em Um estadista do Imperio - que estava disposto a provocar do publico e do Governo argentinos uma solenne manifestação em sua honra. Não sabendo se esse terminante designio chegou a realizar-se, mas vendo nessa declaração a força de uma sentença definitiva, o valor expresso de um reconhecimento, que lhe impõe honrar a memoria do illustre brasileiro; e, sentindo chegar a hora da sua realização, adeantou-se em deixar testemunho da sua devoção ao jurista insigne, gloria do Brasil e da America.

A homenagem é feliz: ajusta-se ao espirito do homenageado. Reproduz a monumental introducção da Consoli- 
dação das Leis Civis, precedida de dois capitulos em que o professor cordobez estuda a vida e a personalidade de TEIXEIRA DE FREITAS e o systema e os principios do direito civil.

O elogio é magistral. Se o jurista bem comprehendeu a doutrina, o biographo viu e sentiu o homem no seu ambiente, acompanhando-lhe a vida, admirando-lhe o caracter e o genio.

Depois de sua morte, escreve, "depois de sua morte, uma memoria, cheia de veneração, conserva o seu nome, e sua fama vae augmentando a tal ponto que, sem hesitação, se póde affirmar que elle occupa o posto mais saliente na historia do pensamento juridico americano; outros existirão de acção mais universal, mais humana, que se hajam agitado e participado mais intensamente das preoccupações de seu tempo, que tenham contribuido, mais efficazmente, para a solução dos problemas nacionaes, mas nenhum, sem excepção, alcançou, como jurista, as alturas escaladas por FREITAS: com elle começa, na America, a linha original da dogmatica juridica, sem que se possa assegurar que os seus continuadores tenham tido o poder de dar-lhe maior esplendor"

Exerceu a obra de TEIXEIRA DE FREITAS immensa preponderancia nos trabalhos de VÉLEZ SÁRSFIELD, quando tomou a si a incumbencia de elaborar o projecto do codigo civil argentino, pela sua originalidade e pela sua precisão scientifica. Deixando imbuir nas doutrinas do jurisconsulto brasileiro, soffreu SÁRSFIELD as criticas amargas do Alberdi. Na resposta, que lhe deu, exarou seu juizo definitivo sobre o incomparavel civilista brasileiro:

"Mas o doutor ALBERDI julgou acertado citar-me exemplos do codigo francez, que, equivocadamente, acredita ter seguido o methodo das Institutas e se engana sobre a preferencia que dei ao senhor Freitas sobre TronCHET, PORTAlis, Maleville. O doutor AlBerdi confessa que não conhece os trabalhos de legislador do senhor FrEITAS e 
parece convencido de que nada melhor possa existir que os jurisconsultos que formaram o codigo francez, tão criticados hoje pelos jurisconsultos da mesma nação. Póde perdoar-me que eu, depois de um sério estudo dos trabalhos do senhor FREITAS, os considere sómente comparaveis com os de SAVIGNY."

O estudo critico, que o professor MARTINez PAZ traçou sobre a introducção da Consolidação das Leis Civis, a que chama de um tratado de systematica juridica, em que o seu autor revela as mais altas qualidades de philosopho e de jurisconsulto, denuncia, logo, o escriptor de raça, seguro na dialectica e profundo nos conhecimentos juridicos. De tal modo se enfronhou da doutrina do autor, que traduziu, que se tem a impressão, lendo-o, de que as paginas antigas revivem, com um colorido novo, que realça o valor das concepções. Enxerga, nos trabalhos de TEIXEIRA DE FrEITAS, principalmente nos referentes á transmissão do dominio, a visão do estadista e a elevação philosophica, a resplandecerem com um brilho tão vivo, como nos documentos juridicos mais altos que tenha produzido o engenho americano.

Da medida exacta da influencia de TEIXEIRA DE FREITAS sobre o codigo argentino, consigna estas notas:

"A proporção exacta de artigos com que contribuiu o Esboço para o nosso codigo foi revelada, depois de uma prolixa e intelligente investigação, pelo doutor LISANDRO SEgovia. Se se considerassem os tres mil e tantos artigos, que comprehendem os tres primeiros livros do codigo argentino, unicos sobre os quaes podia se fazer sentir a influencia de Freitas, se verificaria que um terço delles, isto é, algo mais de mil artigos, foram tomados quasi textualmente.

Esta enorme contribuição, reconhecida expressamente por VÉLEZ, explica porque se omittiu nas notas do codigo constantemente o nome de FrEITAS, a tal ponto que só apparece nas notas correspondentes a dezeseis artigos. 
O interesse que tem o Esboço, entretanto, para os juristas argentinos, não repousa simplesmente no haver dado ao codigo os textos de suas disposições, senão no ser, a seu respeito, um valioso commentario dos mesmos textos. Alludindo a este facto, escreveu o doutor VARELA, com autoridade e exactidão "Bastaria só esta circumstancia para fazer comprehender quão importante é, no estudo de nossa legislação de fundo, o conhecimento da obra de FrEITAS. Nella se encontram não sómente os textos dos artigos que o legislador argentino adoptou, senão tambem a sua explicação e o seu commentario e até as suas concordancias, postos nas copiosas notas com que FreITAS apoia cada uma das disposições do projecto"

Não obstante serem pouco numerosas as citações do nome de FREITAS, ellas accusam, sem embargo, uma delicada adhesão a suas idéas, e elle foi sempre recordado em casos decisivos e em instituições fundamentaes. Assim, ao falar de pessoas juridicas, allude ao titulo projectado por FREITAS e declara que o segue á risca; ao estabelecer os principios de direito internacional privado (artigos $6,7 \mathrm{e}$ 8), ao adeantar um criterio fundamental sobre as cousas (nota 2.311) ; ao criar sobre os factos uma nova fórma de legislação ( secção segunda, nota "a"), isto é, sempre que the foi preciso citar sua suprema autoridade para justificar uma arriscada innovação"

Teixeira de Freitas, como Rio Branco, como JoAQUiM NABUCO, como CASTRO Alves, como RuY BARBosa, fez os seus estudos juridicos nas duas academias brasileiras. Impregnou-se do espirito de ambas ' é um dos que representam as aspirações e as preoccupações dos dois grandes centros de nossa cultura, numes tutelares de ambos.

Prestando-lhe tão significativa homenagem, por occasião do centenario dos cursos juridicos no Brasil, acertadamente andou o professor EnRIQUE MARTINEZ PAZ, pois que cultuou a memoria de um filho dilecto das duas velhas academias do Brasil. 
E veiu trazer mais um elo para essa corrente espiritual, que estamos a fundir, os juristas do Brasil e os da Republica Árgentina, para o entrelaçamento de nossos paizes, ao calor dos ideaes americanos, mercê de um espirito novo, mas já bem vivo, que os ha de engrandecer e fortalecer para que, sempre unidos, possam attingir a sua finalidade historica.

Como brasileiro e como jurista, aqui consigno ao eminente professor argentino a minha inteira solidariedade espiritual e lhe agradeço, de minha parte, a saudação longinqua que nos dirigiu, e a homenagem pessoal que pôz no livro formoso que me offereceu.

Dr. WALDEMar Ferreira.

Professor cathedratico de Direito Commercial. 